\title{
AMBIÊNCIA DOCENTE NO USO DE TECNOLOGIAS DIGITAIS E SEU REFLEXO NA ESCOLHA DE OBJETOS DE APRENDIZAGEM
}

\author{
Milene Selbach Silveira, PPGCC/PUCRS, milene.silveira@pucrs.br \\ Mára Lúcia Fernandes Carneiro, Inst. Psicologia/UFRGS, mara.carneiro@ufrgs.br \\ Lucia Maria Martins Giraffa, PPGEDU/PUCRS, giraffa@pucrs.br
}

\begin{abstract}
Resumo: Recursos digitais educacionais e objetos de aprendizagem (OA) têm sido investigados desde que os Softwares Educacionais surgiram como uma opção para apoiar os processos de ensino e de aprendizagem. Partimos do pressuposto que a experiência prévia do usuário com o uso de tecnologias digitais (TDs) influencia a seleção dos OAs que irão utilizar com seus alunos e que esta seleção geralmente leva em consideração o design de sua interface e sua qualidade de uso. Neste âmbito, são discutidos os achados de uma pesquisa realizada com 11 estudantes de pós-graduação em Educação, experientes no uso de TDs no processo de ensino e de aprendizagem.
\end{abstract}

Palavras-chave: objetos de aprendizagem, interface e interação, tecnologias digitais.

Abstract: Digital Educational resources and Learning Objects (LO) have been investigated since Educational Software arose as an option to support teaching and learning processes. We assume that user previous skills with Digital Technologies (DTs) influence the LO' selection. This selection usually takes in account the interface design and its quality of use. In order to discuss this premise we conducted an investigation with 11 graduate students with experience in the use of DTs in the teaching and learning process.

Keywords: learning objects, interface and interaction, digital technology.

\section{INTRODUÇÃO}

A introdução de novas práticas educacionais associadas as Tecnologia Digitais (TD)1 se alicerça, segundo Gardner (2007), em duas razões básicas: as práticas atuais não estão funcionando de verdade, uma vez que as condições do mundo mudaram significativamente. Como consequência disso, "determinados objetivos, capacidades e práticas podem não ser mais indicados ou podem ate vir a ser considerados contraproducentes” (Gardner, 2007).

Com o advento da Internet e a expansão da Web 2.0 criaram-se novas opções de comunicação e de formação para a sociedade. Não é novidade que esse aumento ao acesso à informação tenha influenciado a maneira como interagimos e, por consequência, a forma que ensinamos e aprendemos.

Alternativas relacionadas a recursos digitais no contexto educacional permeiam a pesquisa em Informática na Educação desde o surgimento dos Softwares Educacionais e suas taxonomias na década de 80 e 90 do século XX, seguidos dos blogs e dos

\footnotetext{
${ }^{1}$ Apesar da sigla TICs (Tecnologias de Informação e Comunicação) ser amplamente usada na área de Informática na Educação, utilizamos neste texto, TD (Tecnologias Digitais) para destacar o recorte adotado no grupo de pesquisa para refletir a especificidade e escopo do tipo de tecnologias que estamos falando: àquelas associadas à Internet e seus serviços e acessadas por meio de artefato digitais.
}

V. $12 \mathrm{~N}^{\mathrm{o}}$ 2, dezembro, 2014 
metaversos em mundos virtuais (Giraffa, 2009). A utilização crescente de espaços digitais colaborativo-cooperativos (plataformas de e-learning) impulsionaram as discussões relacionadas à necessidade de termos, cada vez mais, opções associadas a recursos digitais para apoio as atividades educacionais. E, dentre estes recursos, surgem os Objetos de Aprendizagem (OAs).

O foco do trabalho aqui descrito está na investigação se a experiência pregressa com uso de TDs influencia na seleção de OAs tendo como elementos balizadores da análise as questões referentes à qualidade de uso destes Objetos. Nossa expectativa é que usuários mais experientes possam avaliar e analisar melhor as possibilidades da interface e características dos OAs observados.

Este artigo está organizado na seguinte estrutura: a seção 2 apresenta uma rápida discussão sobre Objetos de Aprendizagem e sua qualidade de uso; a seção 3 descreve a pesquisa organizada e sua relação com a questão da forma como os professores selecionam OAs para apoio a suas atividades. Na seção 4 são apresentadas as considerações finais relacionadas aos achados da pesquisa, restrições e limitações encontradas.

\section{OBJETOS DE APRENDIZAGEM}

Segundo Sosteric e Hesemeier (2002), não existe uma definição consensual sobre o que é um Objeto de Aprendizagem (OA), isso se deve ao fato de que cada grupo de usuários/pesquisadores os conceitua de formas diferentes conforme seus pressupostos teóricos e destinação, bem como da época e tecnologias disponíveis na época da proposição do conceito. A primeira definição adotada é oriunda da IEEE (IEEE 2002; LTCS, 2013): "um objeto de aprendizagem é qualquer entidade digital ou não digital, que pode ser usada, reusada ou referenciada durante a aprendizagem apoiada pela tecnologia”. Gomes et al. (2005) destacam o problema desta abordagem explicando que, com esta definição, "qualquer coisa”, como uma cadeira, ou um teclado de computador, por exemplo, pode ser considerada um Objeto de Aprendizagem.

A ideia principal dos OAs é organizar os conteúdos e atividades para que possam ser reutilizados em outros momentos, em outras situações de ensino, no que tange a implementação e modelagem, baseando-se nos princípios do paradigma de programação orientada a objetos, visando um meio distinto de interação e estruturação da informação. Oakes (2002) conceitua Objetos de Aprendizagem justamente se baseando nesta relação de ensino com a orientação a objetos:

O termo objetos de aprendizagem surge como uma combinação de conceitos de
aprendizagem com o paradigma de orientação a objetos proveniente da área da
computação, objetos são componentes de software que representam abstrações de
entidades do mundo real e que possui duas características fundamentais: autodescrição e
reusabilidade. (OAKES 2002).

O primeiro conceito significa que um Objeto, no universo da computação, é autodescritivo, ou seja, todas as informações e capacidades necessárias o Objeto contém em si disponível para qualquer um que queira utilizá-lo. O segundo conceito diz respeito a um dos principais objetivos do paradigma de orientação a objetos: facilitar a construção de software por meio do reuso, de forma que estes Objetos possam ser usados simultaneamente em diversos sistemas diferentes.

Para Wiley (2000), os Objetos de Aprendizagem são entendidos como entidades digitais disponibilizadas via Internet, de forma que qualquer pessoa possa ter acesso e 
uso, simultaneamente a outros usuários. Os trabalhos de Araújo e Ferreira (2004), Dias et al. (2009), Gomes et al. (2005), Monteiro et al. (2008), Silva e Vicari (2010), Braga, Pimentel e Dotta (2010), Silveira e Carneiro (2012), e Aguiar e Flôres (2014) são exemplos de como a questão relacionada aos OAs tem sido tratada no contexto de IE, no qual a necessidade de se criar ontologias, metodologias, padrões, diretrizes para sua análise e desenvolvimento bem como ferramentas para auxiliar na elaboração de OAs e sua organização nos repositórios pode contribuir para que estes recursos sejam cada vez mais utilizados nos ambientes escolares.

E, para que estes recursos sejam não só cada vez mais utilizados mas também adequados aos objetivos aos quais se propõem, Silveira e Carneiro (2012 apresentam um conjunto de condições para que um determinado recurso educacional seja considerado um Objeto de Aprendizagem digital, condições estas diretamente associadas à qualidade de uso destes recursos: Explicitar claramente um objetivo pedagógico; Priorizar o digital; Prover auxílio aos usuários; Proporcionar interatividade; Proporcionar interação; Fornecer feedback constante; Ser autocontido.

\section{O ESTUDO REALIZADO}

Com vistas a observar como profissionais e estudantes da área de Informática na Educação apropriavam-se e aplicavam critérios de avaliação da interface de materiais didáticos digitais para analisar sua caracterização como Objetos de Aprendizagem, foi organizado um espaço de observação, envolvendo a pesquisa, seleção, observação e análise de um conjunto de materiais didáticos digitais, disponíveis na internet em diversos repositórios. Essa seção apresenta a proposta metodológica para esse espaço, os sujeitos envolvidos bem como o processo de registro, coleta e discussão desses dados.

\subsection{Metodologia}

Para o desenvolvimento desta pesquisa optou-se pela abordagem qualitativa em função das características deste tipo de estudo, o qual permite privilegiar o ambiente natural como fonte de investigação, bem como usar a experiência do pesquisador como instrumento fundamental para guiar as interlocuções com os sujeitos da investigação (Neves, 1996). O trabalho foi desenvolvido a partir de revisão de literatura específica da área e, do ponto de vista de procedimentos técnicos, desenvolvido a partir de um Estudo de Caso. Esse estudo de caso foi constituído a partir da definição de Yin (2001), segundo o qual "o estudo de caso é uma inquirição empírica que investiga um fenômeno contemporâneo dentro de um contexto da vida real quando a fronteira entre o fenômeno e o contexto não é claramente evidente e onde múltiplas fontes de evidência são utilizadas”.

\subsection{Perfil dos Participantes}

Os sujeitos da pesquisa foram 11 alunos de curso de pós-graduação em Educação (nível de Mestrado e Doutorado) e em exercício da docência, sendo que 9 deles (80\%) também atuam na gestão de suas escolas em diferentes funções (diretores, coordenadores ou supervisores). O total de alunos convidados a participar foi 18, dos quais 11 concordaram em participar da investigação.

Os participantes possuem graus de familiaridade e ambiência diversos no que tange ao uso de recursos de TD nas suas atividades docentes. Para manter o anonimato, os participantes passam a ser identificados como P1 ( $1^{\circ}$ Participante) à P11 (11 
Participante). Todos participavam, no momento da pesquisa, de uma disciplina envolvendo o estudo da Formação Docente e Cibercultura, na qual se buscava estudar as questões relacionadas ao novo paradigma que emerge na sociedade relacionado à forma de ensinar e de aprender considerando esta geração de alunos ditos digitais. Já haviam sido realizados trabalhos similares para avaliar como os docentes selecionam recursos digitais apoiadores das suas atividades com seus alunos com outros contextos. Como um dos tópicos da disciplina versava sobre recursos educacionais abertos, Objetos de Aprendizagem e sua qualidade de uso em específico, e, em se tratando de um grupo muito característico - uma vez que reunimos sujeitos com experiências prévias diversas e que haviam recebido formação que lhes habilitava a ofertar os indicadores que desejávamos - a oportunidade de investigação emergiu como complemento aos resultados já obtidos no grupo.

\subsection{O espaço de observação e vivência}

Para constituir esse espaço de observação, os sujeitos foram convidados a escolher - de forma livre - um Objeto de Aprendizagem disponível na Web, e efetuar a análise seguindo instrumento definido para esta investigação.

O registro das avaliações e reflexões dos sujeitos após o uso do Objeto de análise foi realizado com o recurso Formulário do Google Drive. Esse formulário foi organizado com um conjunto de questões fechadas e abertas e estruturado de forma a permitir a possibilidade de anonimato dos respondentes.

No que tange a cuidados éticos e de condução da pesquisa usamos um Termo de Livre e Esclarecido Consentimento, incorporado ao questionário de maneira que todo o participante necessitava primeiro ler o termo e concordar em participar da pesquisa para, somente após esta concordância, ter acesso e responder ao instrumento.

Destaca-se que a participação era voluntária e foi explicitado o objetivo da investigação proposta a saber: influência da experiência no uso de TDs na escolha dos OAs usando como base as informações disponibilizadas na interface e documentação online do Objeto selecionado.

\subsection{Análise dos Dados Coletados}

O formulário de coleta de dados estava constituído por 15 questões, reunidas em 3 blocos: Dados dos Participantes, com questões como área de formação e de atuação (Nome; Área de Formação; Área de Atuação); Utilização do Objeto (Por quê você escolheu este Objeto? Quais características do mesmo determinaram sua escolha? Como este Objeto poderia ser utilizado nas atividades do professor e/ou do aluno? Você conseguiu utilizá-lo com facilidade? Comente como foi a utilização (se ele era intuitivo, se havia instruções de uso, etc); e, Análise do Objeto, com questões relacionadas especificamente às condições descritas no final da segunda seção deste artigo. Por fim, o participante era convidado a apresentar uma apreciação geral sobre o OA escolhido, suas potencialidades e as dificuldades que os usuários poderiam vivenciar no uso.

Os OAs escolhidos envolveram 8 animações e 3 hipertextos, disponíveis em repositórios públicos, como RIVED, NUTED e NAPEAD.

Em relação à escolha e uso do OA, 7 dos 11 respondentes destacaram questões diretamente relacionadas ao seu trabalho e possibilidade de utilizá-lo ou indicá-lo a seus colegas de trabalho nas escolas. Para seleção dos Objetos os respondentes usaram palavras-chave associadas a sua área de expertise ou disciplina que lecionam.

Cabe salientar que os assuntos Objetos de Aprendizagem, Repositórios, Educação Aberta e uso de recursos educacionais abertos já havia sido amplamente 
tratado na disciplina que os alunos cursavam. Ou seja, todos os respondentes já possuíam pré-requisitos que lhes permitissem acessar repositórios e locais na Web nos quais existiam OAs disponíveis. Esta formação prévia facilitou a escolha e o processo e seleção dos OAs, a qual foi intencional e dirigida pelas experiências e constructos prévios dos respondentes. Acredita-se que a formação intencional e reflexiva para uso de recursos digitais é importante e decisiva para o sucesso na adoção de TDs no ambiente escolar. O trabalho de Cerutti (2014) mostrou que professores usuários de TDs no seu cotidiano e com idade que os incluem na categoria de Nativos Digitais postulada nos estudos de Prensky (2001), apesar da sua ambiência com artefatos digitais (especialmente dispositivos moveis conectados à Internet), não conseguem fazer a transposição didática de suas experiências fora da escola para o ambiente escolar. Ou seja, o fato de serem usuários de TDs não lhes garante que saibam criar ou organizar atividades que incorporem OAs ou outros recursos digitais na sua prática docente. Existe um distanciamento entre o comportamento fora do ambiente escolar e o comportamento na escola.

Outros fatores motivadores foram as áreas de atuação e de interesse dos participantes, sendo estes pontos destacados por 5 dos 11 participantes, como podemos ver nas falas de P1 ("Escolhi este objeto de aprendizagem por estar relacionado ao trabalho que desenvolvo (....)”) e P10 ("área de interesse e de pesquisa no curso de mestrado em andamento"), o que ressalta a apropriação dos participantes, a partir de sua formação prévia e vinculada à área de Informática na Educação.

Esta apropriação se sobressai ainda mais quando questionados sobre as possibilidades de utilização do Objeto. Os participantes não se ativeram apenas a descrever possibilidades de uso do Objeto individualmente, mas, também, a sua possibilidade de interligação com diferentes outras atividades, como é possível ver nas seguintes respostas:

Penso que sua maior função é que pode ser usado como ferramenta de produção de texto desenvolvendo habilidades para melhorar a oralidade, criatividade, coerência e coesão textual, leitura entre tantos outros elementos. No meu entendimento é um OA que pode ser usado tanto como "motivador" para o início de um projeto e/ou conteúdo, quanto como instrumento de avaliação do que foi trabalhado já que é possível imprimir o que foi feito. [P2]

Nas aulas complementares de Ciências da Natureza acerca do conceito biomimetismo. Após a exploração do LO o professor poderia elaborar uma WebQuest acerca da temática para que o aluno como tarefa produzisse um material com base no conceito. [P5]

Em aula, usando tablets com fones de ouvido, cada aluno poderia realizar suas descobertas a cerca do mundo sonoro ou ainda utilizando a lousa eletrônica, realizar jogos musicais com o grande grupo. [P6]

Para analisar o conjunto de respostas seguintes - relacionadas às questões sobre utilização do Objeto e possibilidades de interação - os Objetos selecionados foram também avaliados por especialistas na área de Interação Humano-Computador.

O cruzamento desses registros permite afirmar que, no geral, os participantes conseguiram utilizar com facilidade os Objetos por eles escolhidos. Afirmaram que, na sua maioria, os Objetos eram intuitivos, além de alguns apresentarem instruções de uso ou guias para sua utilização. Apenas 2 dos participantes destacaram que, apesar de eles não terem tido problemas na utilização do Objeto escolhido, os usuários finais (professores e alunos que fossem utilizar o Objeto) poderiam tê-lo, como é possível verificar na fala de P6: "Utilizei-o sem problemas mas ele é intuitivo. Creio que, com 
crianças, que é seu objetivo, teriam um pouco de dificuldade, mas ainda assim achei válido no sentido da busca, da pesquisa, das novas descobertas”. E outro dos participantes destacou que, no Objeto por ele escolhido, haviam etapas a serem seguidas ([P1]), mas, na realidade, esse Objeto era constituído por uma estrutura hipertextual, o que pode ter facilitado o entendimento sobre como utilizá-lo.

As questões seguintes relacionavam-se especificamente às condições, anteriormente citadas, para que um recurso digital seja considerado um Objeto de Aprendizagem. Sobre estas condições os participantes foram, então, questionados, no que se referia ao Objeto por eles escolhidos e utilizado.

Quanto à condição "Explicitar claramente um objetivo pedagógico”, que diz respeito ao Objeto propiciar orientações claras para que o aluno saiba o que se espera que ele aprenda ao usar o Objeto e o professor (distinto de quem produziu o Objeto) saiba como poderia usá-lo, podem-se verificar vários pontos interessantes. Apesar de estar descrito que esta condição está relacionada a prover instruções claras sobre o que se espera que o aluno aprenda e o professor desenvolva, mais da metade dos participantes (6 de 11) destacaram ou que estas instruções poderiam ser inferidas do uso ou não eram necessárias ("Como este OA é para crianças, acredito que a falta de instruções não seja um empecilho, visto que as crianças demonstram arriscar mais, sem receios do que poderá acontecer: errar ou acertar uma resposta, por exemplo.” [P6] ) ou apresentaram apenas o objetivo - geral - do Objeto ("O uso do OA tem como objetivo o desenvolvimento de hipertexto sobre fotografia, aplicando as várias categorias destacadas no repositório, bem como saber analisar as diversas tipologias do objeto apresentado.” [P1]). Os demais se apropriaram da condição, identificando se os objetivos pedagógicos estavam ou não explicitados no Objeto ("O objeto explicita o objetivo principal e a que se destina. Logo na introdução apresenta resumidamente o que será abordado. Não identifiquei na apresentação do objeto uma proposta de utilização ou o que se espera desenvolver com sua utilização.” [P7]). Esta apropriação é essencial dado que a condição está diretamente vinculada à concepção e conceito de um OA, considerando-se que a questão da reusabilidade passa pelo entendimento dos objetivos pedagógicos e de como o professor espera que o usuário (aluno) os atinja a partir das ações com o OA.

Quanto a "Priorizar o digital", que diz respeito a priorizar o desenvolvimento de objetos de aprendizagem que não necessitam, para sua utilização, aplicativo ou programa que não esteja disponível gratuitamente na web, a maioria dos participantes ( 7 de 11) conseguiu compreender o conceito. Eles descreveram se o Objeto contemplava ("Contempla este item, pois está disponível na web e não necessita de um software específico para sua utilização, basta um navegador." [P3]) ou não esta condição ("Prérequisitos: Computador ou Tablet e internet. Conhecimentos básicos de Internet. Possuir os softwares Adobe Reader ou similar para abrir textos em formato pdf, navegador de internet atualizado (Internet Explorer, Firefox, Chrome, entre outros)." [P10]). Os demais participantes não explicitaram se precisou ou não de algum outro recurso para utilizar o Objeto selecionado ("Funcionou sem problemas no computador." [P2]).

Quanto a "Prover auxílio aos usuários”, esta condição está associada à existência de recursos que orientem o usuário ao longo do uso e exploração do OA, tanto com recursos de navegação (explicação dos botões, por ex.) quanto com telas de auxílio (ajuda ou help) com orientações detalhadas sobre o uso do próprio Objeto. Praticamente todos os participantes identificaram recursos de auxílio, como glossário, orientações ou instruções de uso. Interessante destacar que alguns relataram só ter buscado pelo recurso 
quando foram analisar a condição, como na fala de [P6]: "Anterior à tela do OA propriamente dito, há uma série de instruções que, sinceramente, inicialmente nem li. Depois que tentei acessá-lo é que voltei e vi que havia uma ajuda para quem precisasse".

Quanto a "Proporcionar interatividade", esta parece ser hoje uma condição essencial para um OA, dado que permite que o usuário deixe a posição de mero "assistente" de uma animação ou "clicador" de uma sequência de botões, para interagir com o Objeto e navegar por ele, conforme seu interesse. Sobre esta condição, a maioria dos participantes (9 dos 11) apontou a existência de recursos interativos. No entanto, um participante, P2, questionou a impossibilidade de "inserir outros objetos e/ou personagens”, indicando sua intenção de explorar e ter acesso a mais recursos do Objeto analisado.

Quanto a "Proporcionar interação", condição relacionada à capacidade de se permitir ações entre os usuários (alunos, professores, tutores, etc.) a partir e/ou no Objeto, houve apenas um problema de interpretação. [P1] apresentou a mesma resposta quando analisou a interatividade e a interação do OA selecionado ("A interação entre os alunos será realizada através de e-mail, SMS, troca de textos eletrônicos, visitas virtuais, sistema Moodle.”), indicando não ter compreendido claramente a diferença entre esses dois conceitos. Os demais participantes identificaram claramente o conceito de "interação" no contexto estudado, e explicitaram várias formas de uso, tanto descritas nos Objetos analisados, ou em propostas por eles elaboradas como possíveis a partir daqueles Objetos selecionados.

Quanto a "Fornecer feedback constante", ou seja, manter o usuário sempre informado do estado atual de sua interação com o OA, foi verificado que alguns participantes parecem não ter compreendido seu significado; talvez por este ser um recurso raramente implementado nos Objetos. O feedback constante é uma condição importante em um OA, pois apoia a sua exploração e uso. Um dos participantes confundiu o feedback com a estrutura hipertextual do Objeto analisado ("as informações serão fornecidas de forma constante e dinâmica", disse P1, sobre um Objeto que não proporciona feedback, e sim é organizado em forma de hipertexto). Outro dos participantes, P10, indicou não ter encontrado esta opção, como esse feedback fosse algo a ser clicado ou buscado no OA, ao invés de ser oferecido constantemente ao usuário.

Quanto a "Ser autocontido", esta condição reflete o fato de o Objeto ter foco em um determinado assunto e o explicar sem necessariamente depender de outros Objetos e/ou materiais. Três participantes apontaram a existência de vários materiais complementares (P3, P7 e P8), mas não conseguiram explicitar se o material contido no próprio Objeto era suficiente para seu uso. Isso pode ser inferido a partir da análise de outras condições, como a explicitação e a clareza do objetivo pedagógico do Objeto. Como nem sempre isso é explicitado, o professor/projetista/implementador acaba fornecendo inúmeros outros materiais complementares, às vezes desnecessários e que acabam confundindo o aluno. Outros participantes, como P9, identificaram claramente essa condição no OA observado, afirmando "sim ... o objeto é ótimo, não necessita de outros objetos ou materiais, apenas permite um desenvolvimento que indica as próximas etapas e próximos objetos que darão continuidade à explicação”.

Após a análise destas condições, os participantes foram convidados a fazer uma apreciação geral sobre o Objeto escolhido, suas potencialidades e, também, as dificuldades que - professores e/ou alunos - que queira utilizá-lo possam vir a ter. Esta 
questão, se comparada às respostas anteriores, permite a análise da coerência das respostas, principalmente considerando a apropriação das condições discutidas. Alguns dos participantes destacaram explicitamente, nesta resposta, itens relacionados às condições discutidas: P2, P3, P7 e P8 destacam a falta de interatividade nos Objetos analisados, sendo que $\mathrm{P} 3$ também destacou a questão do OA por ele analisado não ser autocontido ("É um objeto de qualidade, que apresenta um conteúdo consistente, passível de ser reutilizado e ser adequado a vários contextos, uma característica que julgo relevante. Contudo, não propicia muita interatividade e não é autocontido. Além disso, seu conteúdo está um tanto desatualizado. Acredito que sua utilização junto a um LMS, poderia potencializar o quesito interatividade.”). Outros não são tão explícitos, em relação às condições, mas destacam itens como o Objeto escolhido ser "simples e de fácil acesso" [P4] ou "simples e intuitivo" [P5], ambos destacando o papel do professor na preparação da atividade a ser realizada, ou a necessidade de rever alguns pontos na elaboração do Objeto ("Acho que a única dificuldade está na explicação muito extensa, acho que podia ser mais reduzida e poderia ter sido feita em áudio.” [P9]).

\section{CONSIDERAÇÕES FINAIS}

Dado o escopo e porte do experimento, propomos uma interrogação e não uma conclusão, uma vez que temos ainda (in) conclusões e achados significativos, que nos motivam a seguir adiante na questão da importância da formação tanto docente, bem como dos futuros desenvolvedores de OAs, na questão tão importante que é a qualidade de uso de uma aplicação. Ao concluir a pesquisa e confrontar os resultados que dela emergiram, refletimos sobre o que julgamos importantes contribuições: a transposição das habilidades, atitudes e competências adquiridas com uso diário e massivo de TD não é trivial e não acontece de forma linear. Ou seja, o fato de uma pessoa ser usuária de TD para suas atividades cotidianas não implica que ela transponha estes hábitos e competências para sua atividade profissional.

O trabalho de Cerutti (2014) já apontava que docentes oriundos da geração digital possuem dificuldades de fazer a transposição didática das suas habilidades e competências para selecionar, criar ou aplicar metodologias que contemplem o uso de recursos digitais (sejam OAs ou outros) as suas práticas docentes. Ou seja, deve haver intencionalidade na formação docente para que aconteça esta transposição. Nada se estabelece por pura e simples associação. Os resultados, apesar de serem obtido num grupo pequeno, porém significativo em termos de perfil, apontam para uma situação similar as questões de projeto de interfaces, vinculadas/associadas/transversais às disciplinas de programação. Além disso, permitem estabelecer algumas relações entre as análises apresentadas e os conhecimentos e experiências prévios dos participantes.

Como atividade futura pretende-se expandir o experimento para um conjunto maior de usuários, porém mantendo o mesmo perfil para os respondentes. A escala poderá nos fornecer mais dados para comprovar aquilo que, empiricamente e por observação, já sabíamos: deve existir uma formação com cuidado intencional para que se produzam bons OAs, considerando aspectos computacionais (inclusive as questões de usabilidade). E também deve ser oferecida uma formação de professores que contemple as questões relacionadas ao uso de OAs e outros softwares educacionais, para que estes tenham melhores condições de os selecionarem e utilizarem de forma criativa em apoio a sua prática docente.

A característica principal da área de Informática na Educação é a interdisciplinaridade baseada numa atitude transdisciplinar, pela qual cada parte sabe a 
contribuição que pode fazer para outra. Partir do pressuposto pura e simplesmente não irá contribuir para que tenhamos resultados educacionais mais significativos no que tange a adoção e uso de OAs. É necessário que formemos intencionalmente os profissionais com os requisitos para atividades interdisciplinares complexas com as demandas pelas TD.

\section{REFERÊNCIAS BIBLIOGRÁFICAS}

AGUIAR, E.V.B.; FLÔRES, M.L. Objetos de Aprendizagem: conceitos básicos. In: TAROUCO, L. et alii. Objetos de Aprendizagem: teoria e prática. Porto Alegre: Evangraf, 2014.

ARAÚJO, M.; FERREIRA, M.A.G.V. Construindo uma ontologia para pesquisa de Materiais e Objetos de Aprendizagem baseada na Web Semântica. In: XV Simpósio Brasileiro de Informática na Educação, 2004, Manaus. Anais. Manaus: Sociedade Brasileira de Computação/Universidade Federal do Amazonas, 2004, p. 369-378.

BRAGA, J.C.; PIMENTEL, E.; DOTTA, S. Metodologia INTERA para o desenvolvimento de Objetos de Aprendizagem. In: XXIV Simpósio Brasileiro de Informática na Educação, 2013, Campinas. Anais. Campinas: Sociedade Brasileira de Computação/Universidade Estadual de Campinas. 2013. Disponível em: < http://www.br-ie.org/pub/index.php/sbie/article/view/ 2509/2167>. Acesso em 15 jul. 2014.

CERUTTI, E. Concepções do aluno em relação à docência nos cursos de Licenciatura em tempos de Cibercultura. Porto Alegre, Programa de Pós-Graduação em Educação. PUCRS. 2014. 122p. Tese de Doutorado. Disponível em: <http://hdl.handle.net/10923/5808>. Acesso em 17 jul. 2014.

DIAS, C.C.L.; KEMCZINSKI, A.; LUCENA, S.V.S.; FERLIN, J.; HOUNSELL, M.S. Padrões abertos: aplicabilidade em Objetos de Aprendizagem (OAs). In: XX Simpósio Brasileiro de Informática na Educação, 2009, Florianópolis. Anais. Florianópolis: Sociedade Brasileira de Computação/Universidade Federal de Santa Catarina. 2009. Disponível em:< http://www.br-ie.org/pub/index.php/sbie/article/view/1163/1066>. Acesso em 14 jul. 2014.

GARDNER, H. Cinco Mentes para o futuro. Porto Alegre: Artmed, 2007.

GIRAFFA, L.M.M. Uma odisseia no ciberespaço: O software educacional dos tutoriais aos mundos virtuais. Revista Brasileira de Informática na Educação, v. 17, n. 01, p. 20-30, 2009.

GOMES, S.R.; GADELHA, B.F.; MENDONÇA, A.P.; AMORETTI, M.S.M. Objetos de aprendizagem funcionais e as limitações dos metadados atuais. In: XVI Simpósio Brasileiro de Informática na Educação, 2005, Juiz de Fora, MG. Anais. Juiz de Fora: Sociedade Brasileira de Computação, 2005. p. 201-210.

IEEE. Draft Standard for Learning Object Metadata. Learning Technology Standards Committee of the Institute of Electrical and Electronics Engineers. New York, 2002.

LTCS. IEEE Learning Technology Standards Committee, 2013. Disponível em: $<$ http://ieee-sa.centraldesktop.com/ltsc/>. Acesso em 15 jul.2014.

MONTEIRO, B.S.; PROTA, T.M.; SOUZA, F.F.; GOMES, A.S. Desenvolvimento de objetos de aprendizagem para TVDi. In: XIX Simpósio Brasileiro de Informática na 
Educação, 2008, Fortaleza, CE. Anais. Fortaleza: Sociedade Brasileira de Computação. p. 198-207.

NEVES, J.L. Pesquisa Qualitativa: características, usos e possibilidades. Caderno de Pesquisa em Administração, v.1, n.3, $2^{\circ}$ sem., p.103-113.

OAKES, K. An Objective View of Learning Objects. American Society for Training and Development, v.5, n.56, p. 103-105. 2002.

PRENSKY, M. Digital Natives, Digital Immigrants. On the Horizon. MCB University Press, v. 9, n.5, out. 2001. Disponível em: <http://www.marcprensky.com /writing/Prensky\%20-\%20Digital\%20Natives,\%20Digital\%20Immigrants\%20\%20Part1.pdf>. Acesso em 15 jul. 2014.

SILVA, J.M.; VICARI, R.M. Ampliando as Possibilidades de Uso do Elemento Relation nos Objetos de Aprendizagem. In: XXI Simpósio Brasileiro de Informática na Educação, 2010, João Pessoa, PB. Anais. João Pesoa: Sociedade Brasileira de Computação. Disponível em: <http://www.br-ie.org/pub/ index.php/sbie/article/view/ 1474/1239>. Acesso em 16 jul.2014.

SILVEIRA, M. S.; CARNEIRO, M. L. F. Diretrizes para a Avaliação de Usabilidade de Objetos de Aprendizagem. In: XXIII Simpósio Brasileiro de Informática na Educação, 2012, Rio de Janeiro. Anais. Rio de Janeiro: Sociedade Brasileira de Computação. Disponível em: <http://www.br-ie.org/pub/index.php/sbie/article/ view/1713/1474>. Acesso em 01 nov. 2014.

SOSTERIC, M.; HESEMEIER, S. When is a Learning Object not an Object: A first step towards a theory of learning objects. The International Review of Research in Open and Distance Learning, v.3, n.2. 2002.

YIN, R. K. Estudo de caso: planejamento e métodos. Porto Alegre: Bookman, 2001. 